\title{
Restoring the Natural
}

\author{
${ }^{1}$ Neethu Rajeev, ${ }^{2} \mathrm{~K}$ Radhakrishnan Nair, ${ }^{3} \mathrm{M}$ Arun, ${ }^{4} \mathrm{CS}$ Deviprasad, ${ }^{5}$ Athira A Hari
}

\begin{abstract}
Coronal fractures of the anterior teeth are a commonly found fracture affecting children and adolescents. Management of fractured tooth depends on the availability of the fractured segment, extent of the fracture, and extraoral time of the fragment. If the fractured segment is intact and available, reattachment is an option. Reattachment of fractured tooth fragments can provide immediate and long-lasting esthetics. Additional retention that is needed in some cases is fulfilled by placement of a post. Fiber-reinforced composite post will give better esthetics compared to metallic one. Patient cooperation and understanding of the limitations of the treatment is of utmost importance for good prognosis. This study reports a coronal tooth fracture treated by tooth fragment reattachment with fiberpost reinforcement.
\end{abstract}

Keywords: Dual cure resin cement, Esthetic fiber post, Reattachment.

How to cite this article: Rajeev N, Nair KR,Arun M, Deviprasad CS, Hari AA. Restoring the Natural. Cons Dent Endod J 2016;1(2): 38-40.

\section{Source of support: Nil}

Conflict of interest: None

\section{INTRODUCTION}

Trauma to the anterior teeth resulting in fracture requires immediate attention not only because of the damage caused to the dentition but also due to the psychological impact it has on the patient. ${ }^{1}$ Anterior teeth are most commonly involved in traumatic injuries. Reports say that the prevalence of trauma involving upper central incisors is in the range of 30 to $40 \%$. The treatment varies from simple to complicated restorative intervention, depending on the severity of the fracture and its extent. ${ }^{2,3}$

The reattachment of a fractured fragment was first reported by Tennery ${ }^{4}$ using acid etching technique. Starkey ${ }^{5}$ and Simonsen ${ }^{6}$ have also reported similar

\footnotetext{
1,4,5 Postgraduate Student, ${ }^{2}$ Professor and Head, ${ }^{3}$ Senior Lecturer

${ }^{1-5}$ Department of Conservative Dentistry and Endodontics Azeezia College of Dental Sciences and Research Centre Kollam, Kerala, India
}

Corresponding Author: Neethu Rajeev, Postgraduate Student Department of Conservative Dentistry and Endodontics, Azeezia College of Dental Sciences and Research Centre, Kollam Kerala, India, Phone: +918281420300 , e-mail: neethurajeev2 @gmail.com cases of reattachment. Reattachment of original tooth fragment helps in the immediate repair of the fragment and maintenance of tooth natural appearance, wear resistance, and morphology in the restoration. It evokes a positive emotion and social response from the patient for preservation of natural tooth structure. ${ }^{7}$

There are several factors that influence the management of coronal tooth fractures. They are extent of fracture (violation of biologic width, endodontic involvement, fracture of alveolar bone), fracture pattern and restorability of fractured tooth (presence of root fracture), secondary traumatic injuries (status of soft tissues), availability of fractured tooth fragment and its condition for use (close adaptation between fragment and remaining tooth structure), occlusion, esthetics, expense, and prognosis..$^{8-10}$ Developments and improvement in adhesive techniques and introduction of newer restorative materials made reattachment procedure easier. ${ }^{11}$ Here we are discussing a case report on management of a fractured maxillary right lateral incisor which was treated endodontically, followed by reattachment of the same fragment.

\section{CASE REPORT}

A 33-year-old male reported to the Department of Endodontics with a complaint of fracture of teeth in upper anterior region. The patient had a history of trauma 9 days back. He had sensitivity to hot and cold food.

Clinical examination revealed fracture of the crown at the cervical one-third involving enamel, dentin, and pulp in relation to 12 . Buccally the fracture line was extending $1 \mathrm{~mm}$ subgingivally, and lingually the fracture line was above the cingulam supragingivally (Fig. 1). It was a shovel-type fracture extending from lingual to buccal. Tooth was tender on percussion with crevicular fluid oozing from the buccal margin and fractured part was mobile (Fig. 2). Eleven showed Ellis class I fracture and 21 and 22 showed class II fracture.

A Vitality test of 12 showed an early response to thermal, electrical, and cold test compared to adjacent and contralateral tooth.

Radiographic examination revealed a discontinuity in the middle third of crown involving enamel dentin and pulp in relation to 12. Fracture line was from mesial to distal in oblique line and the periapical area appeared to be normal (Fig. 3).

The case was diagnosed as Ellis class III fracture in relation to 12 . 


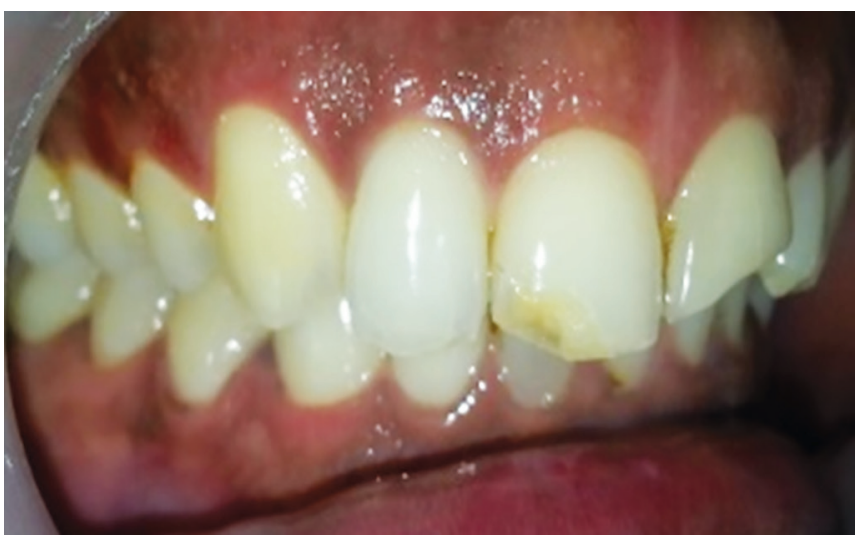

Fig. 1: Preoperative photograph

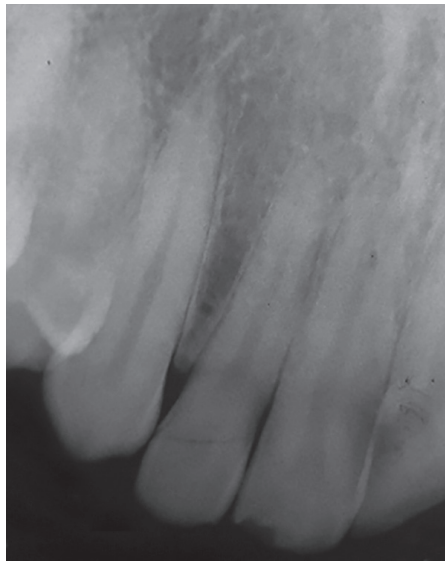

Fig. 3: Preoperative radiograph

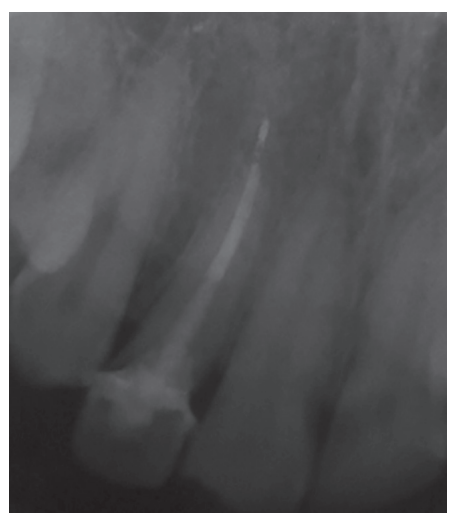

Fig. 5: Postoperative radiograph

It was decided to do root canal therapy along with crown restoration. As the fragment was intact, reattachment was a viable method. After cleaning and shaping, root canal was obturated with master cone size 60 and AH Plus sealer using lateral condensation method.

An apical $4 \mathrm{~mm}$ gutta-percha was retained and post space was prepared. Prefabricated resin esthetic fiber posts of size TFT 11 diameter $1.1 \mathrm{~mm}$ (Tenax Fiber Trans, Coltene/Whaledent) was selected (Fig. 4). The separated tooth fragment needed preparation to accommodate

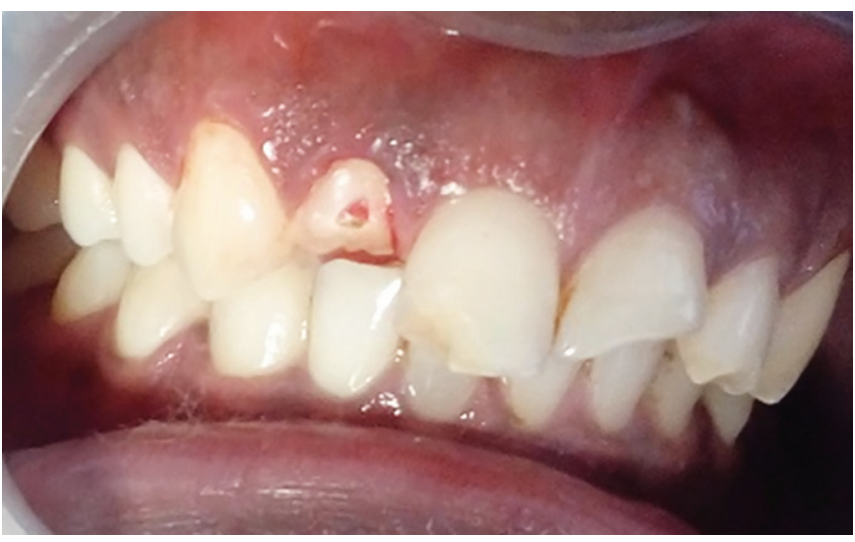

Fig. 2: Image after removal of fractured segment

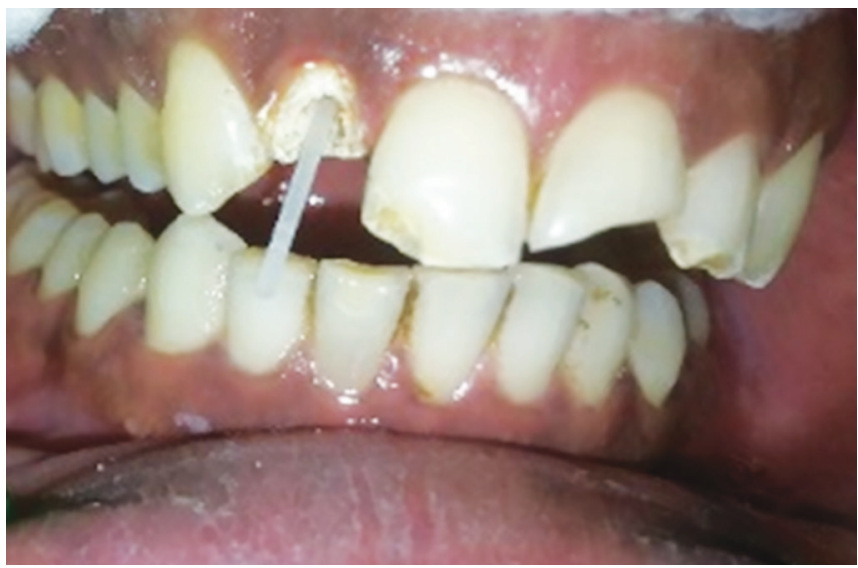

Fig. 4: Placing fiber post

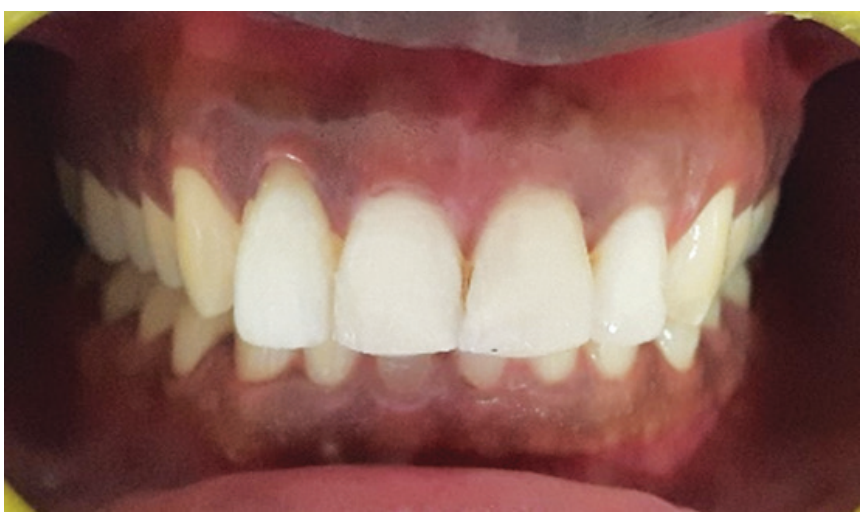

Fig. 6: Postoperative photograph after reattachment, and adjacent teeth restored with composite

the fiber post. The post space was conditioned with ParaBond. The fiber post and the tooth fragment was luted with dual cure resin cement (Para core resin cement, Coltene, Whaledent) (Fig. 5). Adjacent fractured teeth were restored with composite (Fig. 6).

\section{DISCUSSION}

Reattachment is the most conservative, cost-effective, less difficult treatment option for the management of crown fracture. It helps in the immediate repair and restores 
the morphological, functional, and esthetic aspects of the dentition, while maintaining the shape, contour, texture, color, and alignment of the natural teeth. ${ }^{12,13}$

There are various options for fracture reattachment of anterior tooth, depending on the level, type of fracture, and dehydration time of the fragment. Choosing the correct treatment to be followed is based on the patient's age, extent of the fracture (severity and violation of the biologic width), presence or absence of endodontic involvement, tooth fragment availability and its condition of use, occlusion, esthetics, time, and patient expectations. $^{12-16}$

Extraoral dehydration time influences the reattachment procedure. If the extraoral dehydration time is more, less will be the esthetic result and fracture resistance. Proper rehydration of the fragment restores both color and strength. ${ }^{14}$ But here, since the tooth fragment was attached to the tooth itself, chances of dehydration was less. In order to prevent extraoral dehydration time, at the fractured cervical level, additional retention was required for the fractured segment, which was fulfilled by an esthetic fiber post. Fiber post was selected here because its modulus of elasticity is comparable to that of dentin and more esthetic than metal post. Since the fracture line was almost supragingival, a circumferential bevel in enamel and V-shaped notch was given in the dentin for additional retention. Preparing the internal surface increases the fracture resistance of the tooth when compared to direct attachment of fracture segment without any preparation. Dual cure resin cement was used for reattachment procedure since the dual cure mechanism facilitates the insertion and polymerization to the innermost portions of the luting interface. ${ }^{17}$

Reattachment procedure has many disadvantages, such as color changes of the bonded fragment, less esthetic appearance if the fragment is dehydrated for a long time, unpredictable longevity, and may need continuous monitoring. In spite of all these, reattachment is a well-accepted procedure because of its esthetic qualities. Compared to a composite restoration, the incisal edge of the fragment will wear at the same rate similar to that of adjacent teeth.

The remarkable advancement in adhesive systems and resin composites has made reattachment procedure no longer a provisional restoration but rather a conservative restorative treatment offering a favorable outcome. However, this technique is indicated in situations where intact tooth fragment is available and close approximation between fragments is possible. ${ }^{12}$ In the present case, reattachment of the fractured fragment was possible because the separated fragment was intact.

Protection with the use of mouth guard and patient education about limitation of treatment may enhance longterm clinical success, as failure of reattached tooth may occur with new traumatic injuries or parafunctional habits. ${ }^{13}$

\section{CONCLUSION}

A proper treatment strategy based on a sound knowledge of methods and their indications along with risk benefits are needed for an immediate traumatic tooth management. If the fractured segment is available, reattachment procedure offers a better and esthetically pleasing result. With advances in adhesive dentistry and restorative techniques and materials, reattachment procedure became a less difficult challenge in esthetic dentistry.

\section{REFERENCES}

1. Andreasen JO, Andreasen FM. Textbook and Color atlas of traumatic injuries to the teeth. Copenhagen: Munksgaard; 1993.

2. Baratieri LN, Monteiro S. Tooth fracture reattachment: case reports. Quintessence Int $1990 \mathrm{Apr}$;21:261-270.

3. Chu FC, Yim TM, Wei SH. Clinical considerations for reattachment of tooth fragments. Quintessence Int 2000 Jun;31(6):385-391.

4. Tennery NT. The fractured tooth reunited using the acid bonding technique. Tex Dent J 1988;96:16-17.

5. Starkey PE. Reattachment of a fractured fragment to a tooth. J Indiana Dent Assoc 1979;58(5):37-38.

6. Simonsen RJ. Restoration of a fractured central incisor using original teeth. J Am Dent Assoc 1982 Oct;105(4):646-664.

7. Hegede RJ. Tooth fragment reattachment - an esthetic alternative: report of a case. J Indian Soc Pedod Prev Dent 2003 Sep;21(3):117-119.

8. Simonsen RJ. Traumatic fracture restorations: an alternative use of the acid etch technique. Quintessence Int Dent Dig 1979 Feb;10(2):15-22.

9. Reis A, Francci C, Loguercio AD, Carrilho MR, Rodriques Filho LE. Re-attachment of anterior fractured teeth: fracture strength using different techniques. Oper Dent 2001 MayJun;26(3):287-294.

10. Olsburgh S, Jacoby T, Krejci I. Crown fractures in the permanent dentition: pulpal and restorative considerations. Dent Traumatol 2002 Jun;18(3):103-115.

11. Baratieri LN, Monteiro S. Tooth fragment reattachment: fundamentals of the technique and the case report. Quintessence Int 2003 Feb;34(2):99-107.

12. de Castro JC, Poi WR, Pedrini D, Tiveron AR, Brandini DA, de Castro MA. Multidisciplinary approach for the treatment of a complicated crown-root fracture in a young patient: a case report. Quintessence Int 2011 Oct;42(9):729-735.

13. Krastl G, Filippi A, Zitzmann NU, Walter C, Weiger R. Current aspects of restoring traumatically fractured teeth. Eur J Esthet Dent 2011 Summer;6(2):124-141.

14. Maia EA, Baratieri LN, de Andrada MA, Monterio S Jr, de Araujo EM Jr. Tooth fragment reattachment: fundamentals of the technique and two case reports. Quintessence Int 2003 Feb;34(2):99-107.

15. Macedo GV, Diaz PI, de O Fernandes CA, Ritter AV. Reattachment of anterior teeth fragments: a conservative approach. J Esthet Restor Dent 2003;20(1):5-20.

16. Macedo GV, Ritter AV. Essentials of rebonding tooth fragments for the best functional and esthetic outcomes. J Pediatr Dent 2009 Mar-Apr;31(2):110-116.

17. Taguchi CMC, Bernardon JK, Zimmermann G, Baratieri LN. Tooth fragment reattachment: a case report. Oper Dent 2015 May-Jun;40(3):227-234. 